\title{
UN PROCESO DE REFORMA POLÍTICA AD PORTAS DEL BICENTENARIO
}

\author{
JosÉ ANDrÉs Tello Alfaro* \\ Universidad de Lima, Lima, Perú \\ telloalfaroabogados@gmail.com \\ Recibido: 12/10/20 Aprobado: 17/10/20 \\ doi: https://doi.org/10.26439/iusetpraxis2021.n052.5015
}

RESUMEN. Nuestro país afronta hoy en día el primer proceso de reforma política en lo que va del siglo xxı. A diferencia del precedente más cercano (en la década de los noventa), este proceso ahora se da dentro de un Estado de derecho, que a su vez comulga con esta frágil democracia peruana que, en rigor, se identifica con el prototipo de democracia imperfecta latinoamericana. Con esta reforma se persigue una mayor institucionalidad de nuestro precario sistema político. En ese sentido, hemos experimentado tres olas reformistas en lo que va del 2016 al 2020. Dos de estas tienen un origen institucional (comisiones de trabajo creadas especialmente desde el Parlamento y el Poder Ejecutivo para tratar el tema de la reforma) y la tercera proviene de una iniciativa no institucional (propuestas de reformas constitucionales presentadas por el expresidente Martín Vizcarra en julio del 2018). No obstante, quedan algunas dudas sobre su aplicación en el futuro si tenemos en cuenta que las leyes aprobadas por la reforma no han podido ser aplicadas para las pasadas Elecciones Congresales Extraordinarias 2020 y las próximas Elecciones Generales 2021, ni tampoco se ha concluido con el proceso de reforma política a la fecha. En ese contexto, surge la necesidad de finiquitar este proceso de reforma política y, a su vez, replantear algunos aspectos en torno a la necesidad de mantener la no reelección inmediata de autoridades nacionales y subnacionales, quedando en el tintero la posibilidad de permitir hasta una reelección inmediata sin posibilidad de reelección futura.

PALABRAS CLAVE: democracia / democracia imperfecta / institucionalidad / reforma política / reelección / incumbencia / Estado de derecho

\footnotetext{
* Miembro del Instituto Peruano de Derecho Electoral (IPDE). Director ejecutivo del Instituto de Investigación y Capacitación Municipal (INICAM) y profesor de la Universidad de Lima.
} 


\section{A POLITICAL REFORM PROCESS ON THE VERGE OF THE BICENTENNIAL OF PERU'S INDEPENDENCE}

ABSTRACT. Our country currently faces the first political reform process in its history throughout the $21^{\text {st }}$ century. Unlike its closest precedent (in the nineties), this process takes place under the rule of law, which in turn communes with the fragile Peruvian democracy that, strictly speaking, fits the prototype of imperfect Latin American democracy. With this reform, an improved institutional framework of our precarious political system is pursued. In this sense, we have experienced three reform waves from 2016 to 2020, out of which two have an institutional origin (work commissions created especially by the Parliament and the executive branch to deal with the reform) and one has a non-institutional origin (proposals for constitutional reforms presented by former President Martín Vizcarra in July 2018). However, there are still some doubts about the future application of the current political reform-if we take into account that the laws approved by the reform could not be applied either for the past 2020 Extraordinary Congressional Elections or for the next 2021 General Elections-and its process has not concluded to date. In this context, it is required to finish this political reform process and rethink some aspects concerning the need to maintain the prohibition on consecutive reelection of national and subnational authorities. Nevertheless, the possibility of allowing just one consecutive reelection is in the pipeline.

KEYWORDS: democracy / imperfect democracy / institutional framework / political reform / reelection / incumbency / rule of law 


\section{ANTECEDENTES}

Partamos por entender que una reforma política es un proceso sistémico, un proceso integral e interdependiente, en la medida que responde a un criterio teleológico, es decir, la finalidad de la norma o normas que se buscan implementar es tener una clara incidencia en lo que es nuestro sistema político. En ese orden de ideas, hay que tener en cuenta que un sistema político es un espacio natural donde interactúan intereses de diferentes grupos dentro de una sociedad. Su vigencia está claramente relacionada con su funcionalidad dentro de un esquema de entrada de demandas y apoyos sociales, con la salida de decisiones y acciones gubernamentales. Gómez Díaz de León (2015), partiendo de la lógica sistémica de David Easton, nos dice:

De esta forma, para Easton, lo que define a un sistema político es su función de distribuir valores que la sociedad considera útiles, como el dinero, la educación, el poder, etc. (Easton, 2006, p. 111). Dichas interacciones operan mediante flujos entre entradas y salidas (inputs y outputs) a través de un cambio dinámico que se retroalimenta (feedback). Las entradas son las demandas, recursos y apoyos que el sistema recibe de los actores de la sociedad. Estas entradas se trasladan del ambiente social al sistema político responsable de la agregación y articulación de esas demandas, funciones que cumple la caja negra (black box), formada por aquellos que ocupan determinados roles, sean individuos o grupos, los cuales son capaces de orientar los contenidos del proceso político; que actúan como filtro del sistema, a través de mecanismos de reducción y selección de demandas. Los outputs son la respuesta del sistema a aquellas demandas, las decisiones y acciones que se toman tras el proceso de decisión y que, cuando interactúan con el entorno, generan nuevas demandas y apoyos, por lo que el proceso vuelve a comenzar. Este modelo se ha denominado circuito de retroalimentación, o de autorreproducción, o de autoperpetuación (feedback loop), y permite a las autoridades sondear el estado del sistema y corregir errores y perturbaciones. (p. 29)

En resumen, si un sistema político funciona, va a permitir que su sociedad avance en la tramitación de los diferentes intereses que emanan de cada una de sus facciones. Si no funciona, pues hay que cambiar dicho sistema.

Respecto a la eficacia o no de los diferentes sistemas políticos y su relación directa con la democracia, encontramos una reflexión que en los tiempos actuales de la pandemia del COVID-19 hace el Programa de las Naciones Unidas para el Desarrollo (PNUD), Sede Argentina: en lo que va del siglo xxı y hasta el 2010 , las democracias liberales abarcaban la mayoría de los países, ya que representaban el $55 \%$ de 99 países. Sin embargo, en la última década y hasta el 2018, se observó un declive en los regímenes democráticos de más de veinte países, lo que muestra rasgos de autoritarismo en el gobierno de casi un tercio de la población mundial. La base usada por el PNUD fue el índice 2019 de V-Dem, sustentado en indicadores tales como democracia electoral, Estado de derecho, respeto a las libertades individuales, sistema de pesos y contrapesos entre los poderes. 
De acuerdo con este informe del PNUD-Argentina, uno de los desafíos más grandes para la democracia es la lucha contra la exclusión social. La desigualdad económica ha aumentado desde la mitad de la década de los ochenta en la mayor parte del mundo. Con el advenimiento de la crisis sanitaria ocasionada por el COVID-19, rápidamente la economía se transformó y puso en evidencia la desigualdad y exclusión de las personas, lo que agravó el desafío que ya enfrentaba la gobernabilidad democrática.

En una buena parte de Latinoamérica se vienen padeciendo crisis sociales que han llegado a cuestionar fuertemente el modelo democrático. Chile, entre el 2019 y el 2020, es una muestra clara de este proceso, que actualmente es cada vez más notorio. Males colectivos como la corrupción, la inseguridad ciudadana y la insatisfacción de necesidades básicas generan cuestionamientos en torno a una conceptualización de la democracia que va más allá de lo electoral, de lo procedimental, que se refleja en comicios electorales periódicos, y nos traslada a esa visión de la democracia en un sentido amplio. Así lo visualizaron autores como Giovanni Sartori o Guillermo O'Donnell, quienes propugnan la búsqueda de un Estado garante de un real ejercicio de los derechos fundamentales que asisten a cada persona. Al respecto, Zovatto (2011) reflexionaba hace algunos años sobre lo que es una realidad latente y constante en nuestra subregión:

No cabe ninguna duda de que el significativo avance logrado en estos años en materia de elecciones libres y justas, así como en la vigencia y respeto de los derechos humanos y la democratización, es un activo que tenemos que reconocer y valorar. Sin embargo, nuestras democracias acusan déficits importantes, así como grados diversos de fragilidad y enormes desafíos, entre los que destacan los problemas institucionales que afectan la estabilidad política, la gobernabilidad y el Estado de derecho, la independencia y la relación entre los poderes, el funcionamiento de los sistemas electorales y del sistema de partidos políticos, así como los graves problemas de inseguridad ciudadana que convierten a nuestra región en una de las más violentas del mundo. (pp. 50-51)

El Perú no es ajeno a esta realidad latinoamericana y, a pesar de que estamos en lo que Sosa Villagarcía (2016) define como el cuarto impulso de nuestra democracia, aún quedan muchas barreras que superar ${ }^{1}$. En el siglo XXI, hemos asistido a nuestro cuarto proceso de elecciones generales en el 2016. Elegimos un presidente que, luego de un

1 Sosa Villagarcía (2016) realiza un análisis en el que identifica cuatro impulsos en la historia de la democracia:

- Primer impulso: 1939-1948, ligado a términos electorales y liberales.

- Segundo impulso: 1956-1968, después de la caída electoral del presidente Manual A. Odría, relacionada con elecciones y transición del régimen militar a uno civil y el reconocimiento del voto de las mujeres.

- Tercer impulso: 1980-1992, en el marco de las elecciones de la Asamblea Constituyente de 1979 y las elecciones de 1980.

- Cuarto impulso: 2001, tras la caída de Fujimori y el gobierno de transición de Valentín Paniagua. 
intento de vacancia (el 22 de diciembre del 2017) por el Poder Legislativo, renunció el 21 de marzo del 2018 ante una serie de denuncias por presuntos pagos de la constructora Odebrecht, la negociación del indulto a Alberto Fujimori y los kenjivideos, entre otros. Posteriormente, esta renuncia provocó una crisis institucional y agravó el conflicto entre el Poder Ejecutivo y el Poder Legislativo, lo que devino en la disolución constitucional del Congreso de la República (el 30 de septiembre del 2019), y se terminó convocando a las Elecciones Congresales Extraordinarias 2020. Recientemente, la representación política en el Congreso, electa el 26 de enero del 2020, terminó vacando en dos intentos al presidente Martín Vizcarra (el 9 de noviembre del 2020) por el caso Richard Swing y por supuestos hechos de corrupción en el Gobierno Regional de Moquegua. En el 2021, el expresidente Martín Vizcarra postuló como candidato a ese Congreso de la República que tanto cuestionó en su oportunidad.

Es cierto que aún no somos una democracia institucionalizada, plena o máxima, pero, por el contrario, Levitsky (2016) diría que "este ha sido, sin ninguna duda, el período más democrático de la historia peruana. Después de todo ha sido un período de éxito democrático electoral con algunas cosas muy positivas. Aunque las instituciones son muy débiles" (p. 28). Es preciso reconocer que hemos avanzado, aunque falte expandir la ciudadanía en el país: "Esto se debe a que la adquisición de la ciudadanía en el Perú es más un proceso de lucha de grandes sectores de la población contra el Estado, que un proceso de reconocimiento desde las propias instituciones estatales" (Cruz y Román, 2016, p. 50).

Como señala Zovatto (2011), no estamos en la discusión entre autoritarismo o democracia, o sobre el tipo de democracia que buscamos. Hemos pasado a una nueva etapa.

La discusión de nuestros días es sobre la calidad de la democracia, de cómo construir más y mejor ciudadanía, de cómo pasar de una democracia electoral a una de ciudadanos y de instituciones; de cómo conciliar democracia con desarrollo en el marco de sociedades con mayores niveles de cohesión social y mayor equidad de género; de cómo buscar una relación más estratégica entre el mercado y el Estado y una más funcional entre Estado y sociedad; de cómo lograr que la democracia dé respuesta a nuevos tipos de demandas provenientes de sociedades más complejas, más modernas, más urbanas; de cómo hacer funcionar de manera eficaz la democracia en un contexto internacional globalizado. Todos estos temas, como podemos observar, constituyen problemas de la democracia que deben discutirse en democracia y cuya solución debe ser encontrada de manera democrática. (p. 51)

En esa línea de ideas, debemos pasar de la democracia electoral -aunque todavía nos encontramos consolidando dicha democracia- a una democracia de ciudadanos, donde puedan eliminarse las desigualdades sociales, económicas y políticas existentes en nuestra sociedad. La consecución de la paridad y alternancia mejora, en cierta medida, la calidad de la democracia, al hacer efectiva la participación de grupos excluidos, permitiendo cerrar brechas existentes al respecto. 


\section{La reforma política de los noventa (1993-2004)}

Este proceso de reforma política se inició con la entrada en vigencia de la Constitución Política de 1993, que tuvo una serie de normas de desarrollo constitucional tales como la Ley N. ${ }^{\circ}$ 26300, Ley de Control y Participación Ciudadana (LCPC); la Ley N. ${ }^{\circ} 26859$, Ley Orgánica de Elecciones (LOE); la Ley N. ${ }^{\circ} 28360$, Ley de Elecciones del Parlamento Andino (LEPA); la Ley N. ${ }^{\circ}$ 26864, Ley de Elecciones Municipales (LEM); la Ley N. ${ }^{\circ} 27683$, Ley de Elecciones Regionales (LER); la Ley N. ${ }^{\circ} 28440$, Ley de Elecciones de Autoridades de Municipalidades de Centros Poblados (LEAMCP); la Ley N. ${ }^{\circ} 26486$, Ley Orgánica del Jurado Nacional de Elecciones (LOJNE); la Ley N. ${ }^{\circ} 26487$, Ley Orgánica de la Oficina Nacional de Procesos Electorales (LOONPE); la Ley N. ${ }^{\circ} 26497$, Ley Orgánica del Registro Nacional de Identificación y Estado Civil (LORENIEC); y, finalmente, la Ley N. ${ }^{\circ} 28094$, Ley de Partidos Políticos, que hoy en día se conoce como Ley de Organizaciones Políticas (LOP). Este proceso de reforma política duró once años desde 1993 hasta el año 2004.

En toda la normatividad citada encontramos una serie de elementos que son primordiales, los cuales se centran en el carácter dogmático y orgánico que marca el norte de este ordenamiento de desarrollo constitucional posterior a la entrada en vigencia de la Carta Magna de 1993.

En cuanto al carácter dogmático, advertimos el desarrollo de los derechos fundamentales a la participación política, al sufragio y a la asociación política, entre otros. Estos se ven reflejados en la LCPC, que regula los mecanismos de democracia semidirecta en nuestro país ${ }^{2}$; la $L O E$, que regula el sistema electoral vigente para la elección de autoridades nacionales (presidentes, vicepresidentes y congresistas); la LEPA (para parlamentarios andinos), o la LER y la LEM, que a su vez regulan el sistema electoral aplicable a las elecciones de autoridades subnacionales (gobernadores, vicegobernadores, alcaldes y sus respectivos consejos regionales o concejos ediles provinciales y distritales) ${ }^{3}$. No debemos dejar de lado la LEAMCP, que regula la elección de estas autoridades subnacionales reconocidas, pero no consideradas como una instancia de

2 Con relación a los mecanismos de control y participación ciudadana, entramos a la esfera de lo que se conoce como la democracia semidirecta o participativa. Al respecto, Puertas Gómez (1998) señala: “[...] Por su parte, Marcel Prélot nos indica que dicho modelo 'se caracteriza por la presencia, dentro de un sistema que en principio es representativo, de procedimientos que permiten al pueblo intervenir directamente dentro de la actividad legislativa y gubernamental'. En el concepto citado encontramos la idea de que la democracia semidirecta es un régimen esencialmente representativo, complementado con instancias de participación popular directa en las decisiones públicas" (p. 77).

3 Para Valdés Zurita (1997): “El sistema electoral es el conjunto de medios a través de los cuales la voluntad de los ciudadanos se transforma en órganos de gobierno o de representación política. Las múltiples voluntades que en un momento determinado se expresan mediante la simple marca de cada elector en una boleta forman parte de un complejo proceso político regulado jurídicamente y que tiene como función establecer con claridad el o los triunfadores de la contienda, para conformar los poderes políticos de una nación" (p. 13). 
gobierno local por una aplicación del principio de especialidad de la norma que subsana la antinomia constitucional existente entre el artículo 189 y el 194 de la Fundamentalis Lex vigente. En ese orden, apreciamos cómo surge la LOP, que desarrolla justamente el marco normativo de organizaciones políticas de alcance nacional, como lo son los partidos políticos, y de alcance departamental, como lo son los movimientos regionales.

Por otro lado, el desarrollo de la parte orgánica de esta reforma política se traduciría en la dación de las leyes orgánicas de los tres organismos constitucionalmente autónomos: el JNE, la ONPE y el Reniec, gestados en razón de la división del JNE, que constituía originalmente el denominado Poder Electoral. Dicha normatividad dio origen a una serie de conflictos competenciales entre el JNE y la ONPE, los cuales a la larga fueron superados.

Este marco normativo de la reforma, que surgió durante una crisis política como la sufrida por el país en los años noventa, hoy nos coloca en un nuevo escenario de reforma política, una vez más en un período crítico de nuestra historia nacional en razón de los casos de corrupción e inoperancia que afectan a nuestra clase política.

\section{La no reelección de autoridades como política transversal a los procesos de reforma política}

Debemos tener presente que el Perú es un país donde actualmente las autoridades, en promedio, no son pasibles de una reelección inmediata. Eso viene sucediendo desde la caída del régimen de Alberto Fujimori hasta el referéndum confirmatorio del 2018, que estableció un impedimento de reelección inmediata a los congresistas con un $87 \%$ de aprobación ciudadana.

¿Qué se busca con este tipo de medidas?

En principio, el fin es combatir la incumbencia, que es definida por Córdova e Incio (2013) así:

[...] es un fenómeno que da cuenta de la presencia de candidatos a la reelección en un proceso electoral determinado. Los incumbentes son, por tanto, quienes habiendo ejercido un cargo de elección popular se presentan en competencia para renovar su presencia por un período consecutivo de funciones. (p. 418)

Mediante la Ley N. ${ }^{\circ} 27365$, Ley de Reforma Constitucional (del 5 de noviembre del 2000), se modificó el artículo 112 de la Constitución para eliminar la figura de la reelección presidencial inmediata. Dicha medida respondía a la crisis generada por la re-reelección de Alberto Fujimori y el cuestionamiento a las Elecciones Generales 2000.

Queda claro que la incumbencia afectaba el sistema político en la figura de un abuso de la reelección presidencial de Fujimori a finales de los noventa y había que hacer algo al respecto. Empero, hacia el año 2015, cuando se dio el impedimento de reelección 
inmediata de gobernadores regionales y alcaldes, mediante la Ley $N^{\circ} 30305$, Ley de reforma de los artículos 191, 194 y 203 de la Constitución Política del Perú sobre denominación y no reelección inmediata de los gobiernos regionales y alcaldes (del 10 de marzo del 2015), la situación no ameritaba una reforma constitucional que impidiera la reelección inmediata de estas autoridades subnacionales. En la tabla 1, apreciamos el porcentaje de reelección inmediata de los gobernadores regionales/presidentes regionales por año.

Tabla 1

Porcentaje de reelección inmediata de los gobernadores regionales por año

\begin{tabular}{ccc}
\hline Año electoral & Número de gobernadores reelectos & Porcentaje \\
\hline 2006 & 2 & $8 \%$ \\
2010 & 6 & $24 \%$ \\
2014 & 4 & $16 \%$ \\
\hline
\end{tabular}

Elaboración propia con datos extraídos del Infogob (https://infogob.jne.gob.pe/)

Complementando estos datos, tenemos la lista de algunos gobernadores que ejercieron su cargo por dos períodos consecutivos. En este caso, solo se tomó en cuenta la relección inmediata de la autoridad, y no se considera a aquellas que fueron reelectas después de un período. Todos los gobernadores regionales tienen un tiempo máximo de dos períodos de gestión (véase la tabla 2).

Tabla 2

Gobernadores regionales reelectos para dos períodos consecutivos

\begin{tabular}{|c|c|c|c|c|c|}
\hline Región & Nombre & 2002 & 2006 & 2010 & 2014 \\
\hline Áncash & César Joaquín Álvarez Aguilar & & 2006 & 2010 & \\
\hline Arequipa & Juan Manuel Guillén Benavides & & 2006 & 2010 & \\
\hline Ayacucho & Wilfredo Oscorima Núñez & & & 2010 & 2014 \\
\hline Cajamarca & Gregorio Santos Guerrero & & & 2010 & 2014 \\
\hline Callao & Félix Manuel Moreno Caballero & & & 2010 & 2014 \\
\hline La Libertad & José Humberto Murgia Zannier & & 2006 & 2010 & \\
\hline Lambayeque & Humberto Acuña Peralta & & & 2010 & 2014 \\
\hline Lambayeque & Yehude Simon Munaro & 2002 & 2006 & & \\
\hline Loreto & Yván Enrique Vásquez Valera & & 2006 & 2010 & \\
\hline Piura & César Trelles Lara & 2002 & 2006 & & \\
\hline San Martín & César Villanueva Arévalo & & 2006 & 2010 & \\
\hline Ucayali & Jorge Velásquez Portocarrero & & 2006 & 2010 & \\
\hline
\end{tabular}

Elaboración propia con datos extraídos del Infogob (https://infogob.jne.gob.pe/) 
Como podemos advertir, con niveles de reelección por debajo del $20 \%$ en el caso de los gobernadores regionales, se configura la primera evidencia de un exceso normativo al colocar un parámetro constitucional a un elector consciente de a quién sí y a quién no reelegía en instancias subnacionales. No se debió limitar la discrecionalidad del elector con una restricción normativa de alcance constitucional. Lamentablemente, esta situación también se constata en el caso de la reelección de alcaldes provinciales (véase la tabla 3).

Tabla 3

Porcentaje de reelección inmediata de los alcaldes provinciales por año

\begin{tabular}{ccc}
\hline Año electoral & Número de alcaldes provinciales reelectos & Porcentaje \\
\hline 2006 & 27 & $13,8 \%$ \\
2010 & 34 & $17,4 \%$ \\
2014 & 24 & $12,4 \%$ \\
\hline
\end{tabular}

Elaboración propia con datos extraídos del Infogob (https://infogob.jne.gob.pe/)

En detalle, encontramos que algunos alcaldes provinciales tuvieron hasta tres períodos consecutivos de mandato, producto de la reelección en un lapso de cuatro gestiones (2002-2014), como se observa en la tabla 4.

Tabla 4

Alcaldes provinciales reelectos para tres períodos consecutivos

\begin{tabular}{|c|c|c|c|c|c|c|}
\hline Región & Provincia & Nombre & 2002 & 2006 & 2010 & 2014 \\
\hline Áncash & Recuay & Milton Duck León Vergara & & 2006 & 2010 & 2014 \\
\hline Arequipa & Islay & Miguel Román Valdivia & 2002 & 2006 & 2010 & \\
\hline Cajamarca & San Ignacio & Carlos Alfonso Martínez Solano & 2002 & 2006 & 2010 & \\
\hline Junín & Chupaca & Luis Alberto Bastidas Vásquez & & 2006 & 2010 & 2014 \\
\hline La Libertad & Chepén & Ofronio Wilfredo Quesquén Terrones & 2002 & 2006 & 2010 & \\
\hline Lambayeque & Lambayeque & Percy Alberto Ramos Puelles & 2002 & 2006 & 2010 & \\
\hline Lima & Cajatambo & Miguel Ángel Carlos Castillo & 2002 & 2006 & 2010 & \\
\hline Lima & Huarochirí & Rosa Gloria Vásquez Cuadrado & 2002 & 2006 & 2010 & \\
\hline Lima & Yauyos & Diomides Alfonso Dionisio Inga & & 2006 & 2010 & 2014 \\
\hline Piura & Ayabaca & Humberto Marchena Villegas & & 2006 & 2010 & 2014 \\
\hline San Martín & Bellavista & Salvador Campos Rodrigo & 2002 & 2006 & 2010 & \\
\hline Ucayali & Atalaya & Francisco de Asís Mendoza de Souza & & 2006 & 2010 & 2014 \\
\hline
\end{tabular}

Elaboración propia con datos extraídos del Infogob (https://infogob.jne.gob.pe/) 
En el caso de los alcaldes distritales, los niveles de reelección se redujeron entre el 2006 y el 2014 de manera progresiva del $21,9 \%$ al 17,9 \%, algo que indicaba que el elector sabía perfectamente a quién reelegía y a quién no, según se demuestra en la tabla 5.

Tabla 5

Porcentaje de reelección inmediata de los alcaldes distritales por año

\begin{tabular}{ccc}
\hline Año electoral & Número de alcaldes distritales reelectos & Porcentaje \\
\hline 2006 & 353 & $21,9 \%$ \\
2010 & 313 & $19,5 \%$ \\
2014 & 291 & $17,9 \%$ \\
\hline
\end{tabular}

Elaboración propia con datos extraídos del Infogob (https://infogob.jne.gob.pe/)

A pesar de este bajo nivel de reelección, notamos que había un exceso de reelecciones que, a veces, se tornaron emblemáticas, pues algunos alcaldes tuvieron más de cuatro períodos de reelección consecutiva. Sin embargo, eso no justificaba el hecho de establecer una restricción general solo por algunos contados casos en los que el elector, a contrario sensu de la constante en el resto del país (no reeleccionista), tenía la costumbre electoral de reelegir a sus autoridades. Así, por ejemplo, en Chorrillos, Pablo Gutiérrez Weselby fue cuatro veces electo alcalde, lo mismo que Augusto Miyashiro Yamashiro, hoy sucedido por su hijo Augusto Miyashiro Ushikubo. La tabla 6 presenta este y otros casos.

Tabla 6

Alcaldes distritales reelectos para cuatro períodos consecutivos

\begin{tabular}{|c|c|c|c|c|c|c|}
\hline Región & Distrito & Nombre & 2002 & 2006 & 2010 & 2014 \\
\hline Arequipa & Chichas & Tomás Wuile Ayñayanque Rosas & 2002 & 2006 & 2010 & 2014 \\
\hline Ica & San Juan Bautista & Jorge Luis Quispe Saavedra & 2002 & 2006 & 2010 & 2014 \\
\hline Ica & $\begin{array}{l}\text { San Pedro de } \\
\text { Huacarpana }\end{array}$ & Melanio Luis Ayllón Lliuya & 2002 & 2006 & 2010 & 2014 \\
\hline Junín & Pampa Hermosa & Grudy Víctor Galindo Pariona & 2002 & 2006 & 2010 & 2014 \\
\hline Junín & $\begin{array}{l}\text { Santa Bárbara de } \\
\text { Carhuacayán }\end{array}$ & Roque Alejandro Contreras Fraga & 2002 & 2006 & 2010 & 2014 \\
\hline La Libertad & Paranday & Juan Carlos Vilca Taboada & 2002 & 2006 & 2010 & 2014 \\
\hline Lambayeque & La Victoria & Anselmo Lozano Centurión & 2002 & 2006 & 2010 & 2014 \\
\hline Lima & Chorrillos & Augusto Miyashiro Yamashiro & 2002 & 2006 & 2010 & 2014 \\
\hline Lima & Coayllo & Jaime José Vega Ortiz & 2002 & 2006 & 2010 & 2014 \\
\hline Lima & Lurigancho & Luis Fernando Bueno Quino & 2002 & 2006 & 2010 & 2014 \\
\hline
\end{tabular}


(continuación)

\begin{tabular}{lllllll}
\hline Lima & Magdalena & Francis James Allison Oyague & 2002 & 2006 & 2010 & 2014 \\
Lel Mar & San Bartolo & Jorge Luis Barthelmess Camino & 2002 & 2006 & 2010 & 2014 \\
Loreto & Las Amazonas & Aldo Camilo Paino Inuma & 2002 & 2006 & 2010 & 2014 \\
Moquegua & Quinistaquillas & Eleuterio Caytano Coaquira & 2002 & 2006 & 2010 & 2014 \\
Piura & Pacaipampa & Juan Manuel García Carhuapoma & 2002 & 2006 & 2010 & 2014 \\
Tumbes & San Jacinto & José Luis Cornejo Feijoó & 2002 & 2006 & 2010 & 2014 \\
\hline
\end{tabular}

Elaboración propia con datos extraídos del Infogob (https://infogob.jne.gob.pe/)

Finalmente, en el caso de los congresistas, la Ley N. ${ }^{\circ} 30906$, Ley de reforma constitucional que prohíbe la reelección inmediata de parlamentarios de la República (del 4 de octubre del 2018), plantea un fenómeno parecido. Nuevamente se condiciona a un elector que, según la evidencia empírica, sabe reelegir. Si bien hallamos un incremento de la reelección parlamentaria durante los tres últimos procesos de elecciones generales, las cifras no superan el $25 \%$ del total de parlamentarios electos en cada proceso (véase la tabla 7).

Tabla 7

Porcentaje de reelección inmediata de los congresistas por año

\begin{tabular}{ccc}
\hline Año electoral & Número de congresistas reelectos & Porcentaje \\
\hline 2006 & 16 & $13,3 \%$ \\
2011 & 25 & $19,2 \%$ \\
2016 & 29 & $22,3 \%$ \\
\hline
\end{tabular}

Elaboración propia con datos extraídos del Infogob (https://infogob.jne.gob.pe/)

Entre los congresistas reelectos tenemos figuras emblemáticas de los diferentes partidos políticos (véase la tabla 8). Asimismo, encontramos algunos que no tuvieron una participación continua en el Parlamento, pero sí llegaron a formar parte de este en distintos períodos (véase la tabla 9). 
Tabla 8

Congresistas reelectos en períodos consecutivos

\begin{tabular}{|c|c|c|c|c|}
\hline Nombre & 2001 & 2006 & 2011 & 2016 \\
\hline Ángel Javier Velásquez Quesquén & 2001 & 2006 & 2011 & 2016 \\
\hline Carlos Ricardo Bruce Montes de Oca & & 2006 & 2011 & 2016 \\
\hline Cecilia Isabel Chacón De Vettori & & 2006 & 2011 & 2016 \\
\hline Claude Maurice Mulder Bedoya & 2001 & 2006 & 2011 & 2016 \\
\hline Elías Nicolás Rodríguez Zavaleta & & 2006 & 2011 & 2016 \\
\hline José León Luna Gálvez & 2001 & 2006 & 2011 & \\
\hline Luciana Milagros León Romero & & 2006 & 2011 & 2016 \\
\hline Luis Fernando Galarreta Velarde & & 2006 & 2011 & 2016 \\
\hline María Lourdes Pía Luisa Alcorta Suero & & 2006 & 2011 & 2016 \\
\hline Marisol Espinoza Cruz & & 2006 & 2011 & 2016 \\
\hline Rolando Reátegui Flores & & 2006 & 2011 & 2016 \\
\hline Víctor Andrés García Belaunde & & 2006 & 2011 & 2016 \\
\hline Yonhy Lescano Ancieta & 2001 & 2006 & 2011 & 2016 \\
\hline
\end{tabular}

Elaboración propia con datos extraídos del Infogob (https://infogob.jne.gob.pe/)

Tabla 9

Congresistas reelectos en distintos períodos

\begin{tabular}{lllll}
\hline Nombre & 2001 & 2006 & 2011 & 2016 \\
\hline Jorge Alfonso Alejandro del Castillo Gálvez & 2001 & 2006 & 2016 \\
Luz Filomena Salgado Rubianes & 2001 & & 2011 & 2016 \\
\hline
\end{tabular}

Elaboración propia con datos extraídos del Infogob (https://infogob.jne.gob.pe/)

Queda claro que para el Parlamento existía una mayor apuesta por la experiencia de algunos legisladores, quienes, si bien no ejecutan gasto del erario público, son normalmente personas con un alto nivel de representatividad para determinados sectores de la sociedad, en donde mantienen bases fidelizadas. Esto ocurría en el caso de Luciana León, quien tenía bases en Lima Sur, o de Yonhy Lescano, quien tiene bases en Lima Norte y Lima Sur, por lo que fue electo por esta jurisdicción, a pesar de que su jurisdicción de origen era el departamento de Puno.

De manera transversal a todos los cargos de elección popular, hoy sancionados con el impedimento de reelección inmediata, el fenómeno de la incumbencia se podía advertir en el uso de recursos públicos o de posiciones dominantes para lograr una reelección a través de una política clientelar. Así, por ejemplo, el movimiento regional Chim Pum 
Callao copó el Gobierno Regional, la Municipalidad Provincial del Callao y sus distintas municipalidades distritales durante más de dos décadas. Incluso en el Congreso de la República se podía apreciar el manejo político de algunos parlamentarios que buscaban cumplir por medio de sus influencias con ciertas promesas de campaña a sus electores y así recoger nuevamente sus votos cinco años después o, en todo caso, presentarse a las elecciones regionales y municipales. Esto se puede inferir de la muestra cuantitativa sobre la cantidad de proyectos de ley de creación de provincias y distritos, que tuvieron un incremento importante en los años preelectorales y electorales (véase la tabla 10).

Tabla 10

Proyectos de ley de creación de provincias y distritos presentados entre el 2005 y el 2015

\begin{tabular}{cc}
\hline Año & Cantidad de jurisdicciones nuevas que se propone crear \\
\hline 2005 & 3 \\
2006 & 1 \\
2009 & 1 \\
2010 & 1 \\
2011 & 3 \\
2012 & 1 \\
2013 & 10 \\
2014 & 6 \\
2015 & 24 \\
\hline
\end{tabular}

Elaboración propia con datos extraídos del portal del Congreso de la República del Perú (https://www.congreso.gob.pe/)

En la muestra presentada en la tabla 9, se puede notar que las propuestas legislativas de creación de provincias y distritos, que tienen mucho reconocimiento del electorado del interior del país, se incrementaron durante el año preelectoral 2005. En el 2006, como sucede cada veinte años, coincidieron los dos procesos nacionales: las elecciones generales (EG), que se llevan a cabo cada cinco años, y las elecciones regionales y municipales (ERM), con una periodicidad de cuatro años (el 2026 ocurriría un cruce similar de elecciones si se mantiene la misma periodicidad de cinco y cuatro años respectivamente entre ambas; recordemos que una de las propuestas de la reforma política pendiente es justamente homologar los plazos de las elecciones nacionales a cinco años). En los años 2009 (previo a las ERM 2010), 2010 (año electoral y previo a las EG 2011) y 2011, los pedidos de creación fueron moderados. Sin embargo, eso cambia drásticamente el año preelectoral 2013, con diez proyectos de ley; el año electoral 2014 (ERM 2014), con seis proyectos de ley; y el año preelectoral 2015, con nada menos que veinticuatro proyectos de ley, cuando se había sancionado el impedimento de reelección 
inmediata de gobernadores regionales y alcaldes. Para tener un alcance sobre la relación que existiría entre la cantidad de proyectos de creación de jurisdicciones (PCJ) y los posibles casos de incumbencia congresal, debemos revisar la tabla 11.

Tabla 11

Proponentes y número de PCJ que presentaron por cada período entre el 2001 y el 2021

\begin{tabular}{|c|c|c|c|}
\hline Nombre & $2001-2006$ & $2006-2011$ & $2011-2016$ \\
\hline Alan García Pérez (Ejecutivo) & & 1 & \\
\hline Alejandro Aurelio Aguinaga Recuenco & & & 1 \\
\hline Alejandro Toledo Manrique (Ejecutivo) & 1 & & \\
\hline Antonio Medina Ortiz & & & 1 \\
\hline Eulogio Amado Romero Rodríguez & & & 3 \\
\hline Francisco Ccama Layme & & & 3 \\
\hline Hernán de la Torre Dueñas & & & 1 \\
\hline Josué Manuel Gutiérrez Cóndor & & & 2 \\
\hline Juan César Castagnino Lema & & & 1 \\
\hline Julia Teves Quispe & & & 1 \\
\hline Karla Melissa Schaefer Cuculiza & & & 1 \\
\hline Manuel Arturo Merino de Lama & & & 1 \\
\hline Manuel Dammert Ego Aguirre & & & 1 \\
\hline Ollanta Humala Tasso (Ejecutivo) & & & 22 \\
\hline Paulina Arpasi Velásquez & 2 & & \\
\hline Pedro Spadaro Philipps & & & 1 \\
\hline Reber Joaquín Ramírez Gamarra & & & 1 \\
\hline Rosa María Venegas Mello & & 1 & \\
\hline Segundo Tapia Bernal & & & 3 \\
\hline Teófilo Gamarra Saldívar & & & 1 \\
\hline Víctor Edinson Valdez Meléndez & 1 & & \\
\hline Parciales & 4 & 2 & 44 \\
\hline Total & 50 & & \\
\hline
\end{tabular}

Elaboración propia con datos extraídos del portal del Congreso de la República del Perú (https://www.congreso.gob.pe/)

De los 18 congresistas que presentaron proyectos de creación de distritos, solo 3 lograron reelegirse, como se observa en la tabla 12. 
Tabla 12

Proponentes de PCJ y su situación de reelección inmediata

\begin{tabular}{|c|c|c|c|}
\hline Nombres & Período & $\begin{array}{c}\text { Proyectos } \\
\text { presentados }\end{array}$ & $\begin{array}{l}\text { Reeleción } \\
\text { inmediata }\end{array}$ \\
\hline Alan García Pérez (Ejecutivo) & 2006-2011 & 1 & 0 \\
\hline Alejandro Aurelio Aguinaga Recuenco & $2011-2016$ & 1 & 0 \\
\hline Alejandro Toledo Manrique (Ejecutivo) & $2001-2006$ & 1 & 0 \\
\hline Antonio Medina Ortiz & $2011-2016$ & 1 & 0 \\
\hline Eulogio Amado Romero Rodríguez & $2011-2016$ & 3 & 0 \\
\hline Francisco Ccama Layme & $2011-2016$ & 3 & 0 \\
\hline Hernán de la Torre Dueñas & $2011-2016$ & 1 & 0 \\
\hline Josué Manuel Gutiérrez Cóndor & $2011-2016$ & 2 & 0 \\
\hline Juan César Castagnino Lema & $2011-2016$ & 1 & 0 \\
\hline Julia Teves Quispe & $2011-2016$ & 1 & 0 \\
\hline Karla Melissa Schaefer Cuculiza & $2011-2016$ & 1 & 1 \\
\hline Manuel Arturo Merino de Lama & $2011-2016$ & 1 & 0 \\
\hline Manuel Dammert Ego Aguirre & $2011-2016$ & 1 & 1 \\
\hline Ollanta Humala Tasso (Ejecutivo) & $2011-2016$ & 22 & 0 \\
\hline Paulina Arpasi Velásquez & $2001-2006$ & 2 & 0 \\
\hline Pedro Spadaro Philipps & $2011-2016$ & 1 & 0 \\
\hline Reber Joaquín Ramírez Gamarra & $2011-2016$ & 1 & 0 \\
\hline Rosa María Venegas Mello & 2006-2011 & 1 & 0 \\
\hline Segundo Tapia Bernal & $2011-2016$ & 3 & 1 \\
\hline Teófilo Gamarra Saldívar & $2011-2016$ & 1 & 0 \\
\hline Víctor Edinson Valdez Meléndez & $2001-2006$ & 1 & 0 \\
\hline Total & & 50 & 3 \\
\hline
\end{tabular}

Elaboración propia con datos extraídos del portal del Congreso de la República del Perú (https://www.congreso.gob.pe/)

A partir de los datos de las tablas anteriores, podemos hacer un balance cruzando las variables de presentación de PCJ y de postulaciones a las EG 2016 y las ERM 2018, que se aprecia en la tabla 13. 
Tabla 13

Personas que presentaron un PCJ y se postularon a las EG 2016 y a las ERM 2018

\begin{tabular}{|c|c|c|c|c|}
\hline Período & Autoridad & PCJ & EG 2016 & ERM 2018 \\
\hline 2006-2011 & Alan García Pérez (Ejecutivo) & 1 & 1 & 0 \\
\hline $2011-2016$ & Alejandro Aurelio Aguinaga Recuenco & 1 & 0 & 0 \\
\hline $2001-2006$ & Alejandro Toledo Manrique (Ejecutivo) & 1 & 1 & 0 \\
\hline $2011-2016$ & Antonio Medina Ortiz & 1 & 1 & 0 \\
\hline $2011-2016$ & Eulogio Amado Romero Rodríguez & 3 & 0 & 0 \\
\hline $2011-2016$ & Francisco Ccama Layme & 3 & 0 & 0 \\
\hline $2011-2016$ & Hernán de la Torre Dueñas & 1 & 0 & 1 \\
\hline $2011-2016$ & Josué Manuel Gutiérrez Cóndor & 2 & 0 & 1 \\
\hline $2011-2016$ & Juan César Castagnino Lema & 1 & 0 & 0 \\
\hline $2011-2016$ & Julia Teves Quispe & 1 & 0 & 0 \\
\hline $2011-2016$ & Karla Melissa Schaefer Cuculiza & 1 & 1 & 0 \\
\hline $2011-2016$ & Manuel Arturo Merino de Lama & 1 & 1 & 0 \\
\hline $2011-2016$ & Manuel Dammert Ego Aguirre & 1 & 1 & 0 \\
\hline $2011-2016$ & Ollanta Humala Tasso (Ejecutivo) & 22 & 0 & 0 \\
\hline $2001-2006$ & Paulina Arpasi Velásquez & 2 & 0 & 0 \\
\hline $2011-2016$ & Pedro Spadaro Philipps & 1 & 0 & 1 \\
\hline $2011-2016$ & Reber Joaquín Ramírez Gamarra & 1 & 0 & 0 \\
\hline $2006-2011$ & Rosa María Venegas Mello & 1 & 0 & 0 \\
\hline $2011-2016$ & Segundo Tapia Bernal & 3 & 1 & 0 \\
\hline $2011-2016$ & Teófilo Gamarra Saldívar & 1 & 0 & 1 \\
\hline $2001-2006$ & Víctor Edinson Valdez Meléndez & 1 & 0 & 0 \\
\hline Total & & 50 & 7 & 4 \\
\hline
\end{tabular}

Elaboración propia con datos extraídos del portal del Congreso de la República del Perú (https://www.congreso.gob.pe/)

De los 18 congresistas que presentaron proyectos de creación de distritos, 4 (el $22 \%$ de 18) se presentaron a las ERM 2018 y solo 2 (el $50 \%$ de 4) ganaron esa contienda. A su vez, de los 18 congresistas que presentaron proyectos de creación de distritos, 5 (el $28 \%$ de 18) postularon en las EG 2016 como candidatos a congresistas y solo 3 lograron ganar (el $60 \%$ de 5). En total, de los 18 congresistas, 9 se presentaron a las EG 2016 y las ERM 2018, es decir, postuló el 50 \%. En conclusión, si bien no podemos señalar un importante nivel de incumbencia, finalmente sí advertimos la existencia de dicho fenómeno de manera moderada, aunque con una variable que requiere mayor análisis: el incremento de pedidos de creación de nuevos distritos se produce de manera superlativa en el año 2015, cuando se presentaron 24 PCJ, justo el mismo año en que se aprobó 
el impedimento de reelección inmediata para gobernadores regionales y alcaldes. Este hecho, sin duda, puede ser objeto de un mayor análisis en el futuro.

\section{REFORMA POLÍTICA 2016-2019}

Las tres olas de la reforma política que experimentamos en este quinquenio crítico, que está a punto de concluir, previo al bicentenario, nos dejan a priori la sensación de un proceso inconcluso que debería ser terminado, si no por este Congreso en ejercicio, por el siguiente electo en las EG 2021. No obstante, de lo vivido debemos considerar el origen institucional o no de cada una de estas olas reformistas.

La primera ola viene de un impulso primario del Parlamento, que crea el Grupo de Trabajo sobre la Reforma Electoral, adscrito a la Comisión de Constitución y Reglamento del Congreso de la República. Advertimos, entonces, que estamos ante un grupo de trabajo parlamentario y, por ende, se establece el origen institucional per se del proceso de reforma en este estadio. Este grupo de trabajo empezó sus actividades el 23 de agosto del 2016, a menos de un mes del 26 de julio de ese año, fecha en que se instaló aquella representación nacional que fue disuelta el 30 de septiembre del 2020. Estuvo conformado por los parlamentarios Marisol Espinoza Cruz, Gilbert Violeta López, Rosa María Bartra, Yonhy Lescano Ancieta, Zacarías Reymundo Lapa y Javier Velásquez Quesquén. Su producción legal vio la luz entre octubre del 2017 y enero del 2018.

La segunda ola reformista emana de manera abrupta y sorpresiva de cuatro proyectos de ley de reforma constitucional que presenta el presidente de la República, ingeniero Martín Vizcarra Cornejo, el 28 de julio del año 2018. Esta fecha sería inmortalizada como el día en que formalmente se declaró la guerra entre el Poder Ejecutivo y el Legislativo, que terminaría en la disolución de un Parlamento, la elección de uno nuevo y, finalmente, la vacancia de un presidente de la República y la entrada en escena del actual gobierno de transición. Esta ola reformista nos legó tres de cuatro reformas constitucionales aprobadas en un referéndum confirmatorio realizado durante la segunda vuelta de la elección de autoridades regionales el 9 de diciembre del 2018. Estamos evidentemente ante un proceso de reforma política no institucional, en la medida que se originó en una atinada y certera decisión política del Poder Ejecutivo, que, luego de dicho acto, cambió para siempre el correlato de fuerzas en su confrontada relación con el Legislativo.

La tercera ola de reforma política institucional se produce cuando el Poder Ejecutivo crea la Comisión de Alto Nivel para la Reforma Política (CANRP), que depende de la Presidencia de la República mediante la Resolución Suprema N. ${ }^{\circ}$ 228-2018-PCM, publicada el 22 de diciembre del 2018. Dicha comisión estuvo liderada por Fernando Tuesta Soldevilla e integrada por Jessica Bensa Morales, Milagros Campos Ramos, Paula Muñoz Chirinos y Martín Tanaka Gondo. Su trabajo concluyó en la propuesta de doce proyectos de ley. No obstante la expectativa que generó este proceso, a la fecha se encuentra 
inconcluso porque, debido a un cálculo político errado del expresidente Martín Vizcarra, se priorizaron seis de los doce proyectos, y los otros seis quedaron en una agenda que ya dejó de ser prioritaria.

Finalmente, en este contexto, se producen dos hechos de notoria importancia que harían que esta reforma política en tres oleadas quede vigente, pero inaplicada en la práctica: la disolución del Congreso y las Elecciones Congresales Extraordinarias 2020, sumadas a la crisis sanitaria del COVID-19 y sus efectos sobre las Elecciones Generales 2021.

\section{Primera ola reformista}

En el año 2017, se inició un proceso de reforma a través de la Subcomisión de Reforma Electoral de la Comisión de Constitución y Reglamento del Congreso de la República, producto de la cual se aprobarían varias reformas que rigieron para las ERM 2018. Algunas serán aplicadas en las EG 2021. Las reformas aprobadas entre octubre del 2017 y enero del 2018 figuran en la tabla 14.

Tabla 14

Leyes de reforma política aprobadas por el Congreso de la República entre octubre del 2017 y enero del 2018

\begin{tabular}{|c|c|c|}
\hline Ley & Publicación & Sumilla \\
\hline Ley N. ${ }^{\circ} 30673$ & $\begin{array}{l}20 \text { de octubre } \\
\text { del } 2017\end{array}$ & $\begin{array}{l}\text { Ley que modifica la Ley N. }{ }^{\circ} 28094 \text { (LOP), la Ley N. } 26859 \text { (LOE), } \\
\text { la Ley N. } .^{\circ} 27683 \text { (LER) y la Ley N. }{ }^{\circ} 26864 \text { (LEM), con la finalidad } \\
\text { de uniformizar el cronograma electoral }\end{array}$ \\
\hline Ley N. ${ }^{\circ} 30682$ & $\begin{array}{l}18 \text { de noviembre } \\
\text { del } 2017\end{array}$ & $\begin{array}{l}\text { Ley que modifica los artículos } 4 \text { y } 79 \text { de la Ley } N^{\circ} 26859 \\
\text { (LOE) para optimizar el principio de seguridad jurídica en los } \\
\text { procesos electorales }\end{array}$ \\
\hline 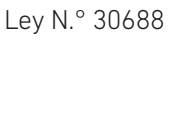 & $\begin{array}{l}29 \text { de noviembre } \\
\text { del } 2017\end{array}$ & $\begin{array}{l}\text { Ley que modifica la Ley } \mathrm{N}^{\circ} 28094 \text { (LOP) y la Ley N. }{ }^{\circ} 26864 \\
(\text { LEM) para promover organizaciones políticas de carácter } \\
\text { permanente }\end{array}$ \\
\hline Ley N. ${ }^{\circ} 30689$ & $\begin{array}{l}30 \text { de noviembre } \\
\text { del } 2017\end{array}$ & $\begin{array}{l}\text { Ley que modifica el Título VI de la Ley N. }{ }^{\circ} 28094 \text { (LOP) y la } \\
\text { Ley } \mathrm{N}^{\circ} \text { 30225, Ley de Contrataciones del Estado, con el fin de } \\
\text { prevenir actos de corrupción y el clientelismo en la política }\end{array}$ \\
\hline 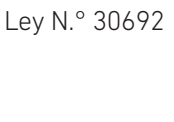 & $\begin{array}{l}5 \text { de diciembre } \\
\text { del } 2017\end{array}$ & $\begin{array}{l}\text { Ley que modifica la Ley } \mathrm{N}^{\circ} 27683 \text { (LER) y la Ley N. }{ }^{\circ} 26864 \text { (LEM) } \\
\text { para regular el vínculo entre el candidato y la circunscripción } \\
\text { por la cual postula }\end{array}$ \\
\hline Ley N. ${ }^{\circ} 30717$ & 9 de enero del 2018 & $\begin{array}{l}\text { Ley que modifica la Ley N. }{ }^{\circ} 26859 \text { (LOE), la Ley } N^{\circ} 27683 \\
\text { (LER) y la Ley }{ }^{\circ} .^{\circ} 26864 \text { (LEM), con la finalidad de promover la } \\
\text { idoneidad de los candidatos a cargos públicos representativos }\end{array}$ \\
\hline
\end{tabular}

Elaboración propia con datos extraídos del portal del Congreso de la República del Perú (https://www.congreso.gob.pe/) 


\section{Segunda ola reformista}

El 9 de diciembre del 2018, se llevó a cabo el referéndum ciudadano confirmatorio con el objetivo de votar a favor o en contra de cuatro reformas constitucionales planteadas por el expresidente Martín Vizcarra ${ }^{4}$. Como resultado del referéndum, se aprobaron tres leyes de reforma constitucional (véase la tabla 15).

Tabla 15

Leyes de reforma constitucional aprobadas como resultado del referéndum ciudadano confirmatorio del 9 de diciembre del 2018

\begin{tabular}{|c|c|c|}
\hline Ley & Publicación & Sumilla \\
\hline Ley N. ${ }^{\circ} 30904$ & 10 de enero del 2019 & $\begin{array}{l}\text { Ley de reforma constitucional sobre la conformación y } \\
\text { funciones de la Junta Nacional de Justicia }\end{array}$ \\
\hline Ley N.ํ 30905 & 10 de enero del 2019 & $\begin{array}{l}\text { Ley que modifica el artículo } 35 \text { de la Constitución Política } \\
\text { del Perú para regular el financiamiento de organizaciones } \\
\text { políticas }\end{array}$ \\
\hline Ley N.30906 & 10 de enero del 2019 & $\begin{array}{l}\text { Ley de reforma constitucional que prohíbe la reelección } \\
\text { inmediata de parlamentarios de la República }\end{array}$ \\
\hline
\end{tabular}

Elaboración propia con datos extraídos del portal del Congreso de la República del Perú (https://www.congreso.gob.pe/)

\section{Tercera ola reformista}

El trabajo efectuado por la Comisión de Alto Nivel para la Reforma Política (CANRP) se materializó en doce propuestas legislativas, presentadas en su informe final. Sin embargo, por los plazos reducidos con los que se planteó la reforma política, desde el Poder Ejecutivo se priorizaron seis propuestas para ser debatidas por el Congreso de la República. Así, el 27 de agosto del 2019, se publicaron en el diario oficial El Peruano cuatro leyes que formaban parte de la reforma política planteada por la CANRP (véase la tabla 16).

$4 \quad$ A los ciudadanos se les consultó lo siguiente:

- ¿Aprueba la reforma constitucional sobre la conformación y funciones de la Junta Nacional de Justicia (antes Consejo Nacional de la Magistratura)?

- ¿Aprueba la reforma constitucional que regula el financiamiento de organizaciones políticas?

- ¿Aprueba la reforma constitucional que prohíbe la reelección inmediata de parlamentarios de la República?

- ¿Aprueba la reforma constitucional que establece la bicameralidad en el Congreso de la República? 
Tabla 16

Leyes de reforma política propuestas por la CANRP y aprobadas por el Congreso de la República

\begin{tabular}{|c|c|c|}
\hline Ley & Publicación & Sumilla \\
\hline Ley N. 30995 & 27 de agosto del 2019 & $\begin{array}{l}\text { Ley que modifica la legislación electoral sobre inscripción, } \\
\text { afiliación, comités partidarios, suspensión, cancelación, } \\
\text { integración y renuncia a organizaciones políticas }\end{array}$ \\
\hline Ley N. 30996 & 27 de agosto del 2019 & $\begin{array}{l}\text { Ley que modifica la Ley Orgánica de Elecciones respecto al } \\
\text { sistema electoral nacional }\end{array}$ \\
\hline 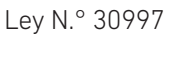 & 27 de agosto del 2019 & $\begin{array}{l}\text { Ley que modifica el Código Penal e incorpora el delito de } \\
\text { financiamiento prohibido de organizaciones políticas }\end{array}$ \\
\hline Ley N. 30998 & 27 de agosto del 2019 & $\begin{array}{l}\text { Ley por la que se modifica la Ley } \mathrm{N}^{\circ} 28094 \text {, Ley de } \\
\text { Organizaciones Políticas, para promover la participación } \\
\text { política y la democracia en las organizaciones políticas }\end{array}$ \\
\hline
\end{tabular}

Elaboración propia con datos extraídos del portal del Congreso de la República del Perú (https://www.congreso.gob.pe/)

\section{Normatividad aplicada durante las Elecciones Congresales Extraordinarias 2020}

El Perú es un modelo clásico de democracia imperfecta, donde, y así se encuentra demostrado empíricamente, los ciudadanos perciben una democracia, un Estado y una institucionalidad débiles. La principal demostración de eso es la baja aceptación ciudadana que tenía la representación nacional en el Congreso de la República. Sin entrar en mayores aspectos propios del análisis político, el 30 de septiembre del 2019, el presidente del Perú Martín Vizcarra disolvió el Congreso de la República y convocó a las Elecciones Congresales Extraordinarias 2020 para el 26 de enero de ese año, a través del Decreto Supremo N. ${ }^{\circ}$ 165-2019-PCM. Esta medida gozó en su momento de una legitimidad social altísima, producto de la coyuntura de conflictividad entre el Poder Ejecutivo y el Legislativo, en la cual el último era percibido como obstruccionista. Una encuesta del Instituto de Estudios Peruanos (IEP) señaló que el 84 \% de los peruanos se pronunció a favor de la medida tomada por el entonces presidente, en referencia a la disolución del Congreso (Huacasi, 2019).

Dicho proceso electoral no se encontraba calendarizado. El marco constitucional y legal previsto solo indica que entre la disolución del Parlamento y las elecciones congresales deben mediar cuatro meses. Tras la disolución y convocatoria a elecciones, se promulgó el Decreto de Urgencia N. 002-2019, norma con rango de ley que estableció medidas urgentes y excepcionales que permiten a los organismos electorales garantizar el desarrollo del proceso electoral. Igualmente, se publicó la Resolución N. ${ }^{\circ}$ 0155-2019-JNE (del 10 de octubre del 2019), que aprueba el cronograma electoral para las Elecciones Congresales Extraordinarias 2020, con lo cual se establecen los hitos 
del proceso electoral y, además, se aplica por primera vez el principio de intangibilidad normativa, dispuesto en el artículo 4 de la LOE, que señala lo siguiente:

Artículo 4.- La interpretación de la presente ley, en lo pertinente, se realizará bajo la presunción de la validez del voto. Todas las normas con rango de ley, relacionadas con procesos electorales o de consulta popular que se publican desde un (1) año antes del día de la elección o de la consulta popular, tienen vigencia el día siguiente de la publicación de la resolución que declara la culminación del proceso correspondiente. Todas las normas reglamentarias relacionadas con procesos electorales o de consulta popular que se publican desde su convocatoria tienen vigencia el día siguiente de la publicación de la resolución que declara la culminación del proceso correspondiente.

Por tanto, todas las normas que habían de ser aplicadas en el proceso de las Elecciones Congresales Extraordinarias 2020 debieron ser aprobadas un año antes de la fecha de la elección, a fin de darle predictibilidad al proceso electoral. Por esa razón, de las cuatro leyes publicadas en el diario oficial El Peruano el 27 de agosto del 2019, en el marco del proceso de reforma política, las tres que se relacionan directamente con la elección congresal no surten efecto para las Elecciones Congresales Extraordinarias 2020, al no haber sido publicadas dentro del plazo establecido en el artículo 4 de la LOE. La inaplicación temporal de estas tres leyes no genera vacíos normativos, porque se aplicarán ultraactivamente las normas vigentes hasta antes de la modificación. Esta situación tuvo como consecuencia que se apliquen normas que incluso se utilizaron en las ERM 2018.

\section{Normatividad para las Elecciones Generales 2021}

Por la crisis sanitaria del COVID-19, el nuevo Congreso de la República, electo en enero del 2020, apenas instalado, promulgó la Ley N. ${ }^{\circ} 31010$, Ley que incorpora una disposición transitoria en la LOE, el 27 de marzo del 2020. Esta ley deja sin efecto para los procesos de abril del 2021 el artículo 4 de la LOE (que establece el principio de intangibilidad normativa) y, además, concede un plazo de seis meses para aprobar las normas (reformas político-electorales) relacionadas con procesos electorales. En mérito de este plazo, que venció el 28 de septiembre del 2020, la Comisión de Constitución, liderada por el congresista de Alianza por el Progreso, Omar Chehade, logró poner en consideración del pleno dentro de esta fecha límite un conjunto de dictámenes, lo que terminó con la promulgación de las leyes que se muestran en la figura 1. 


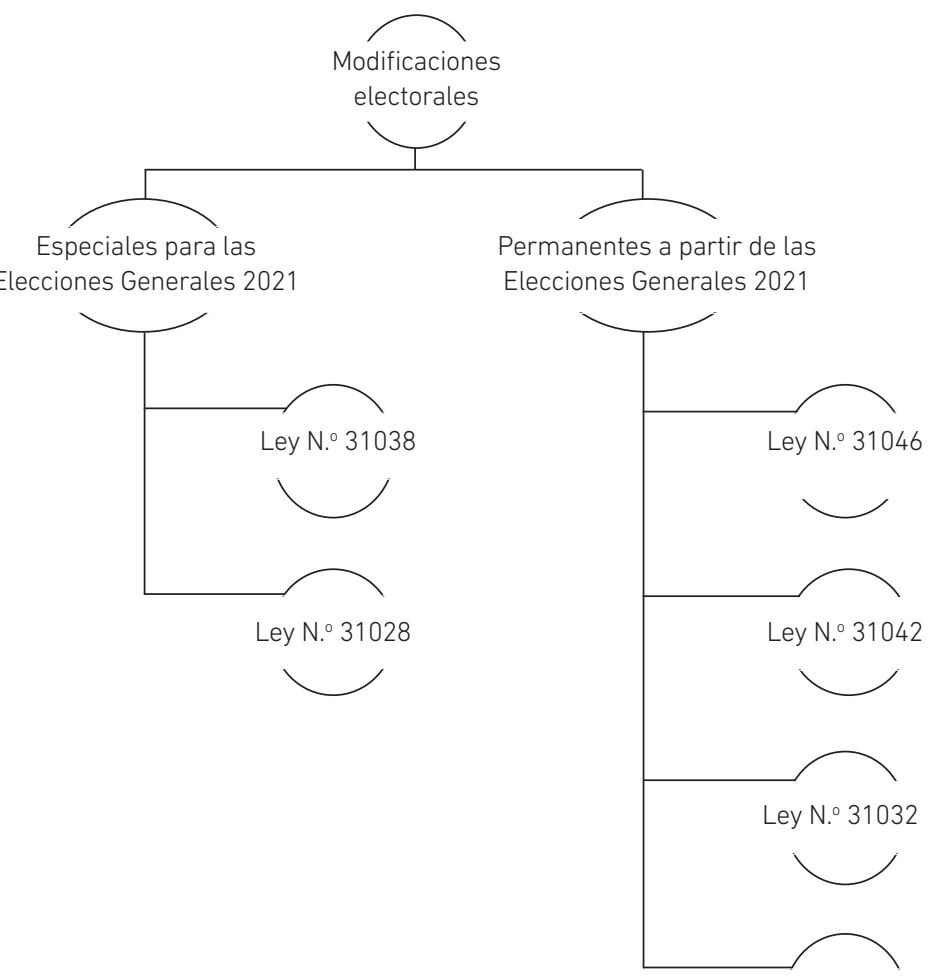

Ley N. ${ }^{\circ} 31030$

Figura 1. Leyes especiales y permanentes aprobadas por el Congreso de la República para las EG 2021

Fuente: Velásquez Javier, Villalobos Campana, Hurtado Cruz y Tello Alfaro (2020)

Las referidas normas desarrollan una temática de carácter permanente o especial, únicamente aplicable para el proceso electoral del 2021, como se observa en la tabla 17. 
Tabla 17

Contenido de las leyes aprobadas por el Congreso de la República para las EG 2021

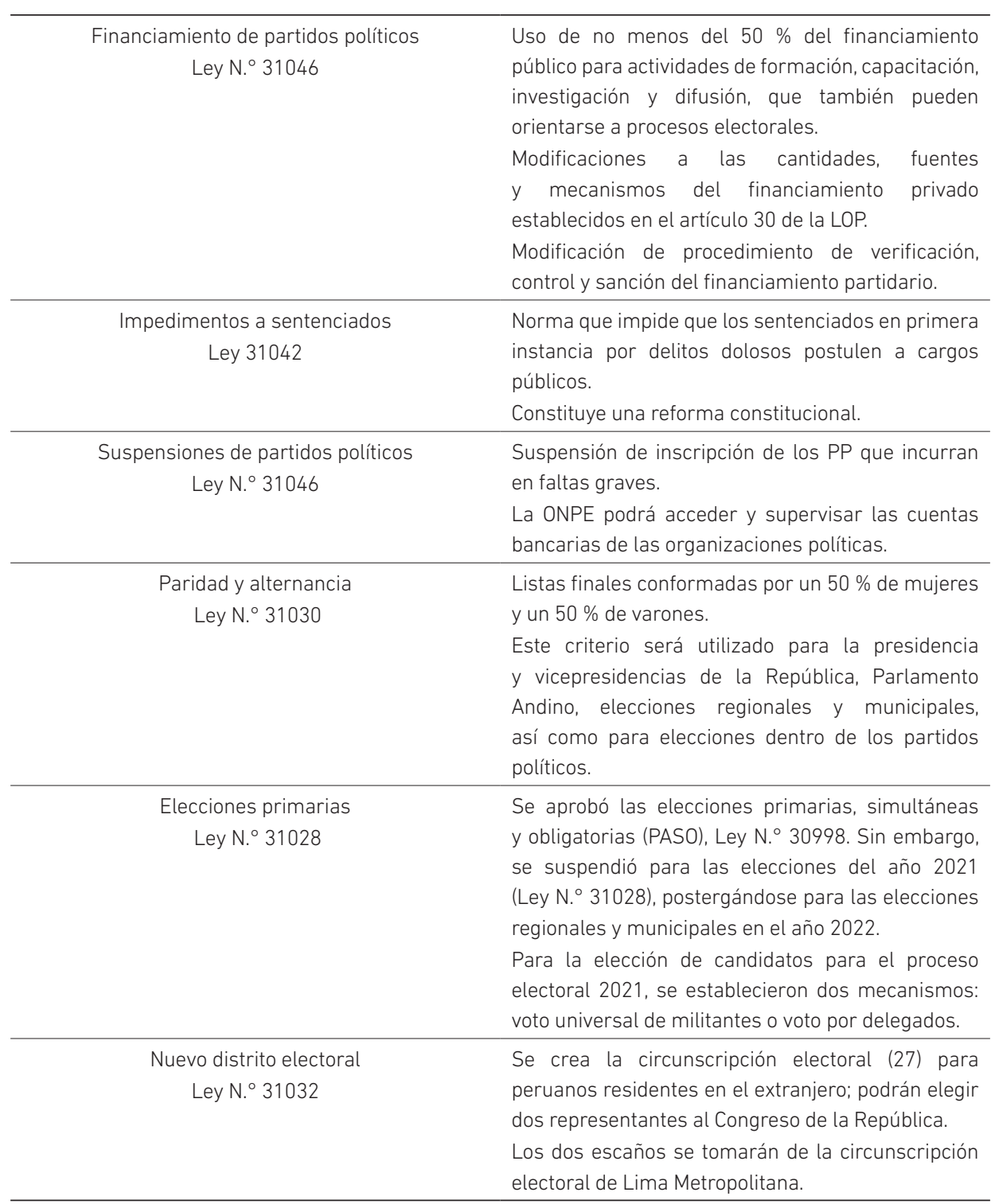

Fuente: Velásquez Javier et al. (2020)

\section{REFORMA PENDIENTE}

A la fecha tenemos una serie de proyectos de ley presentados ante el Congreso de la República, que podrían terminar con el proceso de reforma política que está pendiente 
ad portas del bicentenario. No obstante, el temperamento actual de los congresistas no va en el sentido de sacar adelante estas reformas tan importantes, orientadas a mejorar la gobernabilidad del país en sus tres instancias de gobierno nacional, regional y local. Por ejemplo:

- $\quad$ El PL N. ${ }^{\circ}$ 04185-2018-PE, que propone que el candidato a la presidencia puede postular a congresista; que la renuncia del presidente del Consejo de Ministros implique la renuncia de todo el gabinete; que el número de miembros del Congreso se base según la población electoral y que, por ende, se regule por ley; la eliminación de la famosa causal de incapacidad mental.

- El PL N. ${ }^{\circ}$ 04193/2018-PE, que establece que se recibirá un aguinaldo del 1,5\% de una UIT por ser miembro de mesa; se amplía el margen de acción de la ONPE para gestionar el proceso electoral; se habilitan más lugares de votación; se debe implementar, progresivamente, el voto por correo.

- El PL N..$^{\circ}$ 4194/2018-PE, que amplía legalmente el mandato a cinco años de las autoridades regionales y locales; homologa la fecha de las elecciones al primer domingo del mes de noviembre; adiciona un consejero regional más por cada 100000 habitantes inscritos en el padrón electoral, además de los siete consejeros mínimos; precisa que todos los candidatos deben ser elegidos al interior del partido; igualmente, indica que se asignará el $40 \%$ de los escaños de consejeros regionales a los partidos más votados; asimismo, que en los lugares donde se aplique la cuota indígena, el cargo público asignado será solo de un representante de la cuota; en caso haya dos, se usará la cifra repartidora.

- El PL N. ${ }^{\circ}$ 04195/2018-PE, que le proporciona más funciones de control a los consejeros regionales y regidores (para fiscalizar gestión); homologa las causales de vacancia y suspensión de las autoridades regionales y municipales, etcétera.

- El PL N..$^{\circ}$ 04196/2018-PE, que modifica los artículos 191 y 194 de la Constitución para ampliar el mandato de cuatro a cinco años de las autoridades regionales y locales. De esa manera, quedarían homologados los gobiernos nacionales y subnacionales.

Sin embargo, a la fecha estos proyectos de ley continúan pendientes (véase la tabla 18) 
Tabla 18

Estado de los proyectos de ley de reforma política en el Congreso de la República

\begin{tabular}{|c|c|c|c|}
\hline N. ${ }^{\circ}$ & Código & Nombre & Situación procesal \\
\hline 1. & 04185/2018-PE & $\begin{array}{l}\text { Proyecto de ley de reforma constitucional } \\
\text { para promover la gobernabilidad y } \\
\text { fortalecer la democracia }\end{array}$ & $\begin{array}{l}\text { Pendiente, comisión: } \\
\text { Constitución y Reglamento }\end{array}$ \\
\hline 3. & 04193/2018-PE & $\begin{array}{l}\text { Proyecto de ley que modifica la Ley } \mathrm{N}^{\circ} \\
26859, \text { Ley orgánica de elecciones para } \\
\text { establecer facilidades para el sufragio de } \\
\text { la población en condiciones especiales, } \\
\text { precisar el principio de neutralidad } \\
\text { y garantizar una mejor elección del } \\
\text { proceso electoral }\end{array}$ & $\begin{array}{l}\text { Pendiente, comisión: } \\
\text { Constitución y Reglamento }\end{array}$ \\
\hline 4. & 04194/2018-PE & $\begin{array}{l}\text { Proyecto de ley que modifica la Ley } \\
\text { de Elecciones Regionales y la Ley } \\
\text { de Elecciones Municipales, sobre los } \\
\text { sistemas electorales regionales y } \\
\text { municipales }\end{array}$ & $\begin{array}{l}\text { Pendiente, comisión: } \\
\text { Descentralización, Regionalización, } \\
\text { Gobiernos Locales y Modernización } \\
\text { de la Gestión del Estado }\end{array}$ \\
\hline 5. & 04195/2018-PE & $\begin{array}{l}\text { Proyecto de ley que modifica la Ley } \\
\text { Orgánica de Gobiernos Regionales y } \\
\text { Control por los Consejos Regionales y } \\
\text { Concejos Municipales }\end{array}$ & $\begin{array}{l}\text { Pendiente, comisión: } \\
\text { Descentralización, Regionalización, } \\
\text { Gobiernos Locales y Modernización } \\
\text { de la Gestión del Estado }\end{array}$ \\
\hline 6. & 04196/2018-PE & $\begin{array}{l}\text { Proyecto de ley de reforma constitucional } \\
\text { que modifica los artículos } 191 \text { y } 194 \\
\text { de la Constitución sobre el período de } \\
\text { mandato regional y municipal }\end{array}$ & $\begin{array}{l}\text { Pendiente, comisión: } \\
\text { Descentralización, Regionalización, } \\
\text { Gobiernos Locales y Modernización } \\
\text { de la Gestión del estado }\end{array}$ \\
\hline
\end{tabular}

Elaboración propia con datos extraídos del portal del Congreso de la República del Perú (https://www.congreso.gob.pe/)

\section{CONCLUSIÓN}

Estamos ante un proceso de reforma política que se encuentra inconcluso, a pesar de haber consumido grandes recursos logísticos y políticos en lo que va del quinquenio 2016-2021, que ya termina. Es importante señalar algunos aspectos medulares:

1. En primer lugar, este tipo de reforma se ha dado en un contexto donde la institucionalidad, la credibilidad de nuestra clase política, la corrupción e ineficiencia del gobierno han puesto a prueba nuestra democracia imperfecta, pero sobre todo nuestro Estado de derecho, el cual se ha visto llevado al límite, pero no colapsado, incluso afrontando cuatro pedidos de vacancia presidencial (dos a Pedro Pablo Kuczynski y dos a Martín Vizcarra), la renuncia de dos presidentes (Pedro Pablo Kuczynski y Manuel Merino de Lama), la vacancia de un 
presidente (Martín Vizcarra), una presidencia interina (Francisco Sagasti), un Parlamento disuelto, una elección congresal extraordinaria y una nueva representación nacional electa para el período de mandato complementario a aquel interrumpido con la disolución del anterior Congreso de la República electo el año 2016. A pesar de toda esta convulsión política, que incluso tuvo una incontenible protesta ciudadana, las Fuerzas Armadas se han mantenido no deliberantes y tampoco han asumido su histórico rol de tutela de la democracia (militarismo), quedando, como corresponde, sometidas al poder civil constituido en las urnas (hecho que demuestra la consolidación de este proceso de sometimiento democrático expresado desde que David Waisman Rjavinsthi se convirtió en el año 2001 en el primer ministro civil de Defensa de la historia de nuestro país).

2. Segundo, la reforma política ha tenido para Martín Vizcarra en su ejercicio de la presidencia de la República una utilidad política, un eje temático de su gobierno que no se condice con su propia trayectoria, pues decidió reformar un sistema de partidos políticos siendo él independiente, sin afiliación política a ningún partido; y equilibrar los niveles de gobernabilidad entre poderes del Estado (Poder Ejecutivo y Legislativo) sin tener una bancada en el Congreso y solo gobernando con el poderoso apoyo ciudadano y respaldo político de los gobernadores regionales y alcaldes del país. Empero, es un proceso importante que da vida orgánica a nuestro sistema de partidos en períodos electorales y no electorales, que genera competitividad electoral, que efectivamente coadyuva a balancear las relaciones entre los poderes del Estado, y homologa períodos de mandatos entre autoridades nacionales y subnacionales, lo que da lugar a una estandarización en los mecanismos de control político (suspensiones y vacancias) entre autoridades regionales y municipales, etcétera. Son muchas las ventajas que ofrece la reforma política pendiente de ser concluida como para quede sin ver la luz por una escasa o nula voluntad política del actual Congreso o el próximo, que se instalará el 26 de julio del 2021. En consecuencia, dicho proceso, reiteramos, debe concluir.

3. Tercero, convencidos de que la reforma debe continuar y terminarse, consideramos que es positiva la incorporación de temas como la bicameralidad (que no hemos podido desarrollar en el presente trabajo) o la posibilidad de hasta una reelección inmediata de autoridades como congresistas, gobernadores regionales y alcaldes, siempre y cuando se mejoren también los mecanismos legales y normativos que eviten o palíen los efectos de la incumbencia de las autoridades en ejercicio del cargo que postulan a una reelección inmediata frente a aquellos candidatos que lo hacen sin estar en el ejercicio del poder. Creemos que, por efectos de la curva de aprendizaje, los bajos niveles de 
reelección que tiene el elector peruano en promedio (inferiores en general al $25 \%$ en autoridades nacionales y subnacionales), entre otros factores, harían que dicha medida sea saludable y coadyuve a la gobernabilidad de un país que no requiere de un marco normativo restrictivo (basado en el impedimento), sino quizás limitativo (basado en el número de veces), en torno a la justa y legítima competencia electoral por el poder. En el caso de la reelección del presidente de la República, la situación se presenta de una manera más compleja tras la huella que dejó el gobierno de Alberto Fujimori y su abuso de la figura de la reelección presidencial. Creo que, si bien en rigor no podemos soslayar la posibilidad de tentar hasta una sola reelección presidencial, colocar este tema en agenda, de momento, podría entrampar políticamente el debate sobre la reelección en las otras instancias antes mencionadas.

4. Y, por último, indistintamente de las mejoras o cambios que podamos hacer en nuestra normatividad con relación a la regulación del sistema electoral o político, nunca vamos a poder sustraer al elector de su rol de elegir bien y con eso sentenciar su destino como gobernado por el plazo que dura el mandato de aquel candidato al que convirtió en autoridad. Por ende, el deber ciudadano está en emitir un voto consciente, sustentado en una elección racional y no emotiva, al momento de concurrir a las urnas.

\section{REFERENCIAS}

Córdova, B., e Incio, J. (2013). La ventaja del incumbente en el ámbito subnacional: un análisis de las dos últimas elecciones municipales en Perú. Papeles Políticos, 18(2), 415-436. Recuperado de http://www.scielo.org.co/pdf/papel/v18n2/ v18n2a02.pdf

Cruz, M., y Román, A. (2016). La democracia peruana: apreciaciones e hipótesis desde la escuela. Argumentos. Revista de Análisis y Crítica, 10(2), 49-58. Recuperado de https://argumentos-historico.iep.org.pe/wp-content/uploads/2016/06/CRUZ ROMAN_JULI02016.pdf

Gómez Díaz de León, C. (2015). Sistema político y formas de gobierno. En Ciencia política: perspectiva multidisciplinaria (pp. 19-48). Ciudad de México: Tirant lo Blanch.

Huacasi, W. (6 de octubre del 2019). 84 \% respalda disolución constitucional del Congreso. La República. Recuperado de https://larepublica.pe/politica/2019/10/06/cierredel-congreso-84-respalda-disolucion-constitucional-del-parlamento/

Levitsky, S. (2016). La precaria continuidad democrática peruana. Argumentos. Revista de Análisis y Crítica, 10(2), 27-34. Recuperado de https://argumentos-historico.iep. org.pe/wp-content/uploads/2016/06/LEVITSKY_JULIO2016.pdf 
Puertas Gómez, G. (1998). Democracia e instituciones de democracia semidirecta. Una aproximación teórico-conceptual. Justicia Electoral. Revista del Tribunal Electoral del Poder Judicial de la Federación, 11, 71-83. Recuperado de https://tecnologiaseducativas.te.gob.mx/RevistaElectoral/content/pdf/a-1998-02-011-071.pdf

Sosa Villagarcía, P. (2016). Los impulsos de la democracia peruana y sus variedades. Argumentos. Revista de Análisis y Crítica, 10(2), 41-48. Recuperado de https:// argumentos-historico.iep.org.pe/wp-content/uploads/2016/06/SOSA_ JULI02016-2.pdf

Valdés Zurita, L. (1997). Sistemas electorales y de partidos. Ciudad de México: Instituto Federal Electoral.

Velásquez Javier, V. A., Villalobos Campana, J. M., Hurtado Cruz, V. I., y Tello Alfaro, J. A. (2020). Manual para candidatos. Elecciones Generales 2021. Lima: Instituto Peruano de Derecho Electoral, Democracia y Gestión Pública.

Zovatto, D. (2011). Democracia y gobernabilidad en América Latina en el siglo xxı temprano. Ciudad de México: Tribunal Electoral del Poder Judicial de la Federación. 